\title{
Materializing Identity-A Statistical Analysis of the Western Zhou Liulihe Cemetery
}

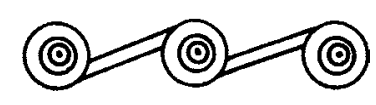

YITZCHAK JAFFE

\section{INTRODUCTION}

Following The CONQUest of the Shang State in the latter half of the eleventh century B.C., the Zhou polity set out to establish a firmer hold on its newly occupied territories. The victors began a swift campaign of colonization, including sending members of the royal family to defend and expand strategic zones around the new realm (Shaughnessy 1999:311-312). Land was given to kin of the Zhou king who had been charged with establishing a Zhou presence in the region. Many of these newfound domains gained power and later become independent states that dominated the region during the Eastern Zhou period (770-221 вC) (Shaughnessy 1999:314).

Many of the areas conquered by the Zhou were already inhabited by indigenous peoples; Zhou material culture was only gradually incorporated into these areas (Li 2006:78-79). After surveying over 20 Western Zhou states, Hsu and Linduff (1988:163) concluded that Zhou elites typically formed the upper echelons of the newly stratified societies after the Zhou had imposed their social order on local populations.

Our understanding of the identity of the Zhou peoples and their origins has been greatly expanded through analysis of mortuary data in conjunction with reading textual sources; much Western Zhou archeological data comes from mortuary contexts. Work done on burial assemblages has focused on stylistic comparisons that measure change and local developments with the goal of determining cultural uniqueness as well as external cultural influences. Several works dealing with spatial arrangements of cemeteries have uncovered links between disparate familial groups and lineages (Shaughnessy 2004). ${ }^{1}$ Other studies have analyzed identities associated with government power and bureaucratic appointments (Li 2008). However, most archeological reconstructions of society during the Western Zhou period have been concerned with determining the ethnic or supra-cultural identity of cemetery occupants. Through the stylistic examination of burial goods, researchers generally ascribe one of three identities to cemetery occupants: Zhou, Shang, or a local ethnicity (Beijing 1995; Luoyang 2002; Shandong 1982). ${ }^{2}$

These analyses have successfully described the political culture, delineated administrative and kinship ties, and provided important information on elite taste and 


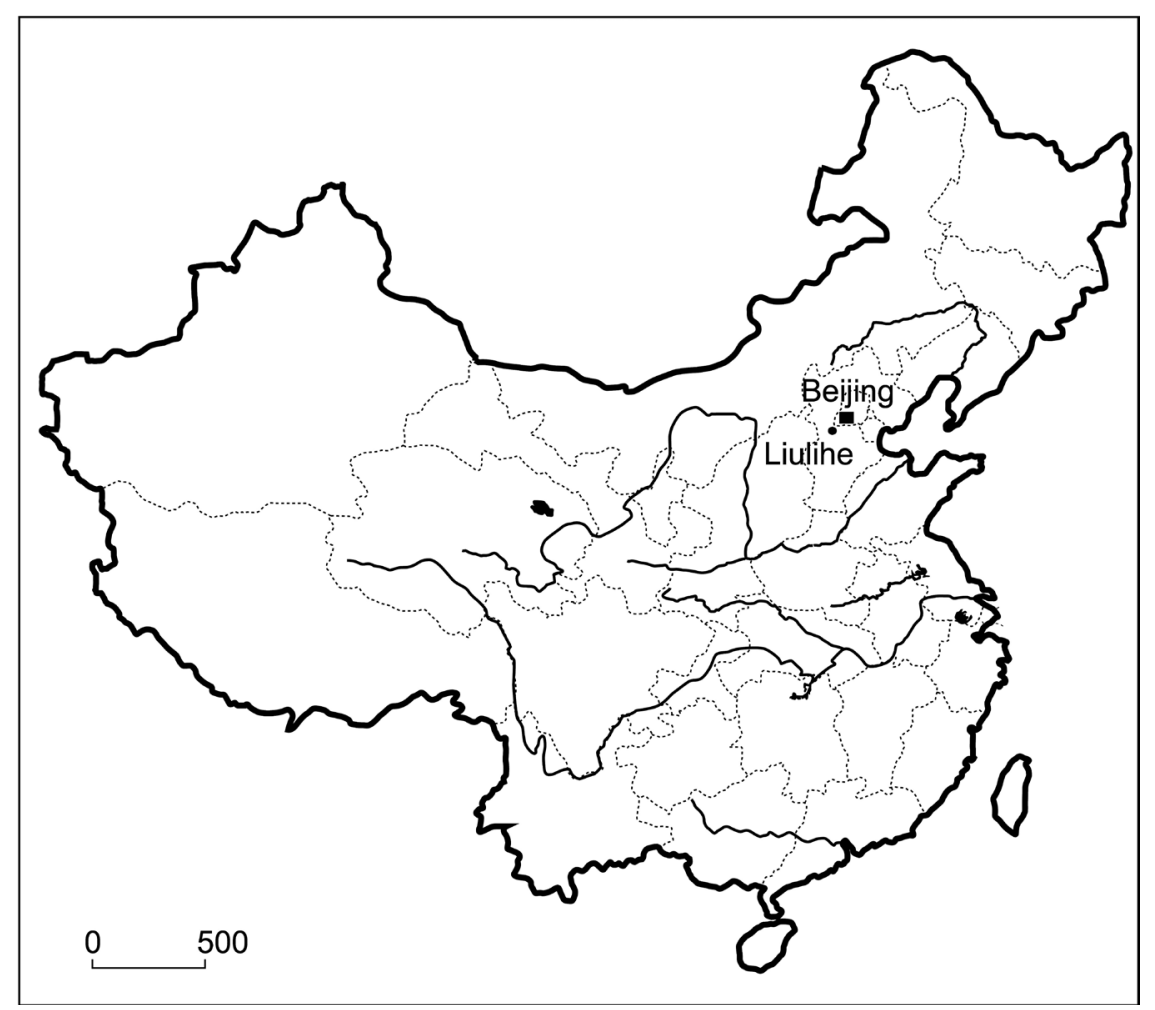

Fig. 1. Map showing the location of the Liulihe site.

customs during the Western Zhou period. They have paid less attention to uncovering other social groupings and relations, however, and have not systematically addressed the ways in which local identities were exercised or displayed. In addition, many researchers have criticized ascribing ethnic identity purely on the basis of material culture (von Falkenhausen 1995; Hodder 1978; Insoll 2007; Meskell 2001; Meskell and Preucel 2004; Pearson 1999; Shelach 2009; Shennan 1989).

This article expands upon previous approaches to delineating Zhou political elements and ethnic characteristics. The Liulihe (琉璃河) cemetery located in Hebei Province, part of the Yan (燕) state (Liulihe being the capital), during the Western Zhou period (1045-771 B.C.), provides a test case (Fig. 1). Using multivariate statistical tools, I uncover new elements comprising the complex social makeup and identity of the Liulihe occupants and provide a richer understanding of Yan society.

\section{THE ZHOU EXPANSION: VIEWS FROM THE YAN POLITY}

The endowment inscription on the Ke lei (克罍) bronze vessel excavated from the Liulihe cemetery provides an exceptional glimpse into how the Zhou endowed land as well as how the non-Zhou populace was perceived by the Zhou court. It describes how the Zhou king bestowed the rulership of the new state of Yan on Ke, probably 
the son of the Duke of Shao (燕召公) (Li 1997). According to the inscription, the king said, “'Grand Protector, you have brightened your fragrant wine and offered it to your monarch. I greatly respond to your offering, commanding Ke [克] to be ruler in Yan [燕], to govern the Qiang [姜], Ma [侀], Zha [慮皮], Yu [馭] and Chang [長].' Ke arrived at Yan, took in [its] land and its officials, and herewith makes [this] treasured sacrificial vessel" (Li 2008:241-242). The inscription states that both the land and its people have come under the authority of a Zhou court representative, but it differs from standard inscriptions portraying the establishment of a new state. For example, the inscription on the Yihou Ze gui (宜侯失篮) describes the land and people of Yi being given to a ruler from Zheng (鄭) who brought with him several of the king's men, some elders and their servants, and members of the local Zheng local population. The new ruler of $\mathrm{Yi}$ (宜) created his administrative body from central court members, whereas the new ruler of Yan integrated members of the local ruling elite in his regime (Li 2008:240-243).

According to archaeological research, the Datuotou (大陀头), Zhangjiayuan (张家园), and Lower Xiajiadian (夏家店) Bronze cultures thrived in this region prior to Zhou conquest (Wu 2004 : 203). Several pre-Zhou burials found near Liulihe provide clues about the mixed origins and other characteristics of the Liulihe residents. These graves exhibit bronze items comparable to contemporary Shang types found in the central plain; other items such as gold earrings and bracelets typical of the Lower Xiajiadian culture are also present (Hsu and Linduff 1988:198-199).

Guo (1996) argues that latter phases of Lower Xiajiadian culture should be identified as pre-Yan. The discovery of a pre-Zhou stratum at Liulihe along with Lower Xijiadian burials points to the pre-existing Yan state granted in early Zhou times to the Duke of Yan. Later Zhou styles were integrated with these pre-Yan elements to produce a new cultural type (Guo 1996:178). This conclusion is based on the distinct $l i$ (鬲) vessel type found in the lower stratums at the Liulihe site. The $y u$-shaped $l i$ (孟形鬲) vessel was common in Lower Xiajiadian burials; the yan-type li (燕式鬲) found in the Liulihe cemetery is considered a development of this vessel type (Guo 1996: 154).

This notion of continuation, development, and incorporation of local culture is not unique to Guo. In his investigation of Lower Xiajiadian culture, Li argues that the third phase of Weifang culture mixed with Western Zhou culture to create the Yan culture (Li 2000:164). The Shang influence and aggressive expansion in the twelfth and eleventh centuries B.C. are viewed as chief factors in the decline of Lower Xiajiadian culture during its latter Hulugang phase (Li 2004:194). During the late Shang period, Lower Xiajiadian culture was replaced by Upper Zhangjiayuan culture, which was firmly established in the area around the Juma River (拒马河) (Li 2004:195). ${ }^{3}$ This reconstruction ascribes a minor role to Lower Xiajiadian culture in the rise of Yan culture, since it would already have ceased to exist in the area by the time the Yan state was established.

Controversy still exists regarding the identification of a number of bronze hoards and burials from the late Shang and early Western Zhou cultures found in this area (Wu 2004:203). Most of the graves and hoards display a mix of 'Shang' Western Zhou and Northern style bronze vessels and weapons along with other artifacts such as Northern-style gold bracelets (Wu 2004). Some sites contain predominately Northern-style artifacts. The differences among these burials point to the complex cultural matrix of the region. The data has given rise to many different theories about 
the identity of the occupants of these graves and the ethnic and social makeup of the time. Four explanations for these findings are as follows:

1. Both Shang and Zhou cultures spread into and influenced existing cultures in the region;

2. Shang bronzes were brought by refugees who fled after the Shang were defeated by the Zhou;

3. Bronzes in hoards were hidden and abandoned by fleeing bureaucrats and rulers; or

4. All of the artifacts belonged to the local population (Wu 2004:207-208).

Wu (2004) argues against these simplistic explanations and argues that the Zhou expansion changed the northern Bronze cultures by integrating the Zhangjiayuan culture, while the Shanrong (山戎) culture in the mountains became a rival of the new Yan state. Meanwhile, the Upper Xiajiadian culture dominated the area north of the Yan mountains; it was only absorbed during the later Eastern Zhou period (Wu $2004: 210$ ). However, this scenario does not explain how the Yan rulers integrated local material culture with their own.

Bronze inscriptions distinguish between rulers of Zhou satellite states who were related to the Zhou royal lineage (considered true Zhou states) and rulers of other affiliated states. Even though Yan was founded by a branch of the royal Zhou family, its material culture was heavily influenced by local cultures. This observation, along with the relative distance of Yan from the center of Zhou politics, suggests a scenario whereby the Yan developed their own material culture along with distinct political affiliations. Indeed, this has led some scholars to describe the Yan culture as a melting pot of surrounding cultures (Barnes 1999:135-136).

Other researchers argue that the Zhou had a more pivotal role in the creation of Yan culture. Li states that "the Zhou constituted a bronze culture that developed by assimilating the Shang and other indigenous cultures, but it emerged as a distinctive culture that like the early Shang found expression in its bronzes" (Li 2004:198). Sun Yan's (2001) work on the nature and style of bronze and jade artifacts further supports Li's argument that the Western Zhou's impact on material culture was both definitive and unifying. Bronzes at the Liulihe cemetery display similar features in design, pattern, and style, and in the composition of their inscriptions. That is, their "common features ... far outnumber their differences" (Li 2004 : 198).

\section{PREVIOUS WORK AT THE LIULIHE CEMETERY}

The majority of the data concerning the Western Zhou state of Yan comes from the Liulihe site, where excavations have been conducted over the past 40 years. A number of projects have taken place since the first excavation season between the years 1973 and 1977 (Beijing 1995; Beijing and Beijing 1996a; Beijing et al. 2000; Zhongguo et al. 1984). A large city wall, moats, drainage systems, and residential areas have already been unearthed. Most notably, a cemetery including 26 chariot pits and over 200 burials has been excavated, including tomb M1193 attributed to the Duke of Yan (Beijing and Beijing 1996a, 1996b).

All the graves found in the Liulihe cemetery are rectangular. Most of them contain an ercengtai (二层台), or stepped ledge where burial goods were displayed (Fig. 2). Several of the richer graves have ramps leading down to rectangular tombs; some 


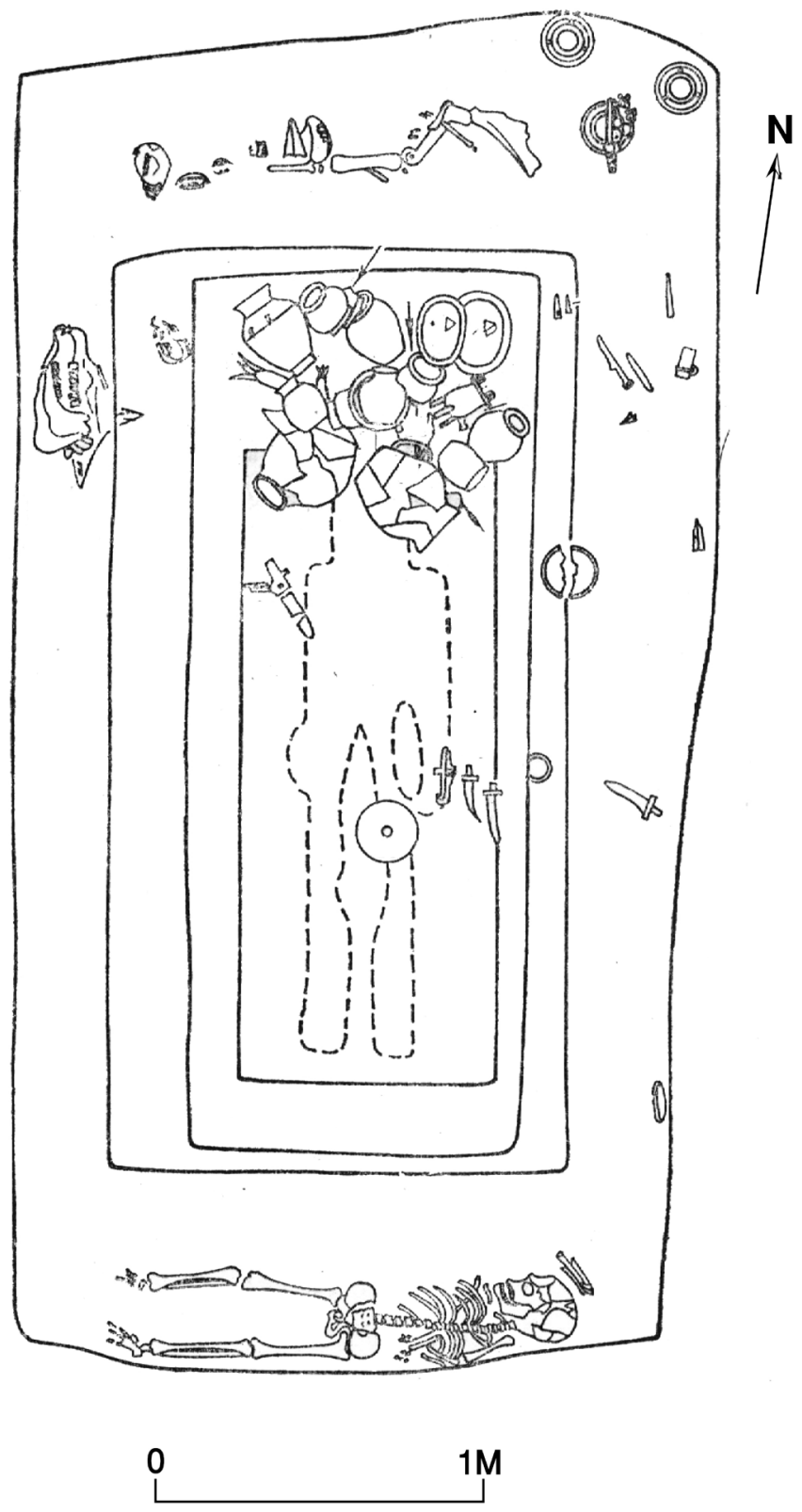

Fig. 2. A typical grave in the Liulihe cemetery. (Beijing $1995: 24)$

of the graves contain a smaller and shallower pit called a yaokeng (腰坑) or waist pit (Beijing 2995; Sun 2001). ${ }^{4}$

The graves of the Liulihe cemetery were found in two main clusters dubbed areas I and II (Fig. 3).

The excavators view these clusters as more important than simple locational preference. They have found significant differences in the burial styles of the two areas as reflected in burial goods and mortuary practices. Based on evidence of dog and 


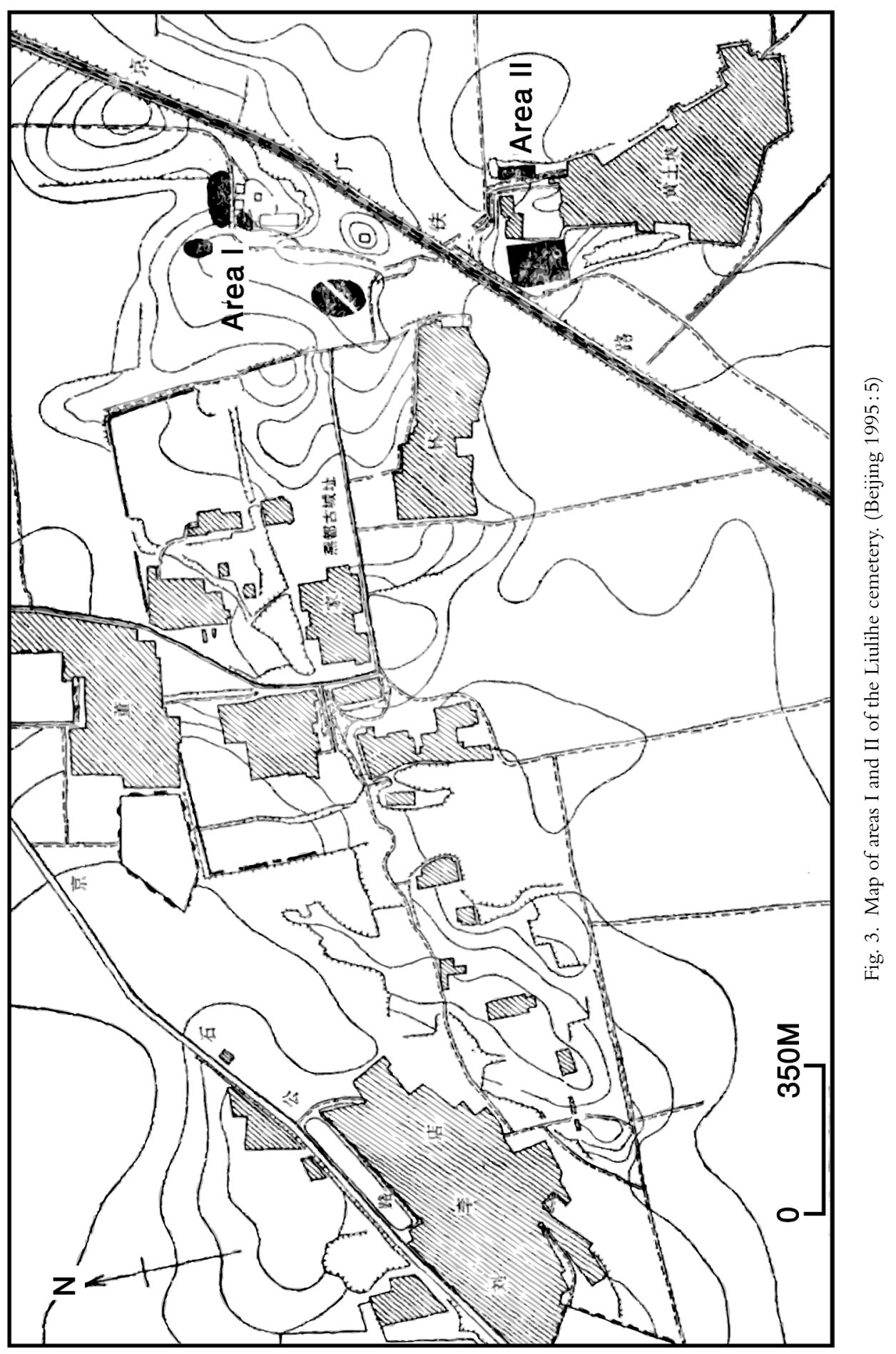


human sacrifice (commonly associated with Shang burial customs) and the large quantity of Shang-style $l i$ tripods found, the ethnic identity of area I occupants is considered Shang, or locals observing Shang burial rituals. Strengthening this identification are Shang-type lineage symbols inscribed on two bronze vessels (one zun 尊 and one pan 盘) in grave IM52 in area I (Beijing 1995:251).

In contrast, graves in area II follow the burial styles of the Western Zhou. Fewer $\operatorname{dog}$ and human sacrifices were found and the li and guan (罐) pottery vessels were closer in style to that of the Zhou type found in the central plain. Several bronze inscriptions further point to a political link with the Zhou court. For example a bronze ding (鼎) from grave IIM253 contains an inscription concerning a Yan marquis sending an emissary to the Zhou court; two other vessels, a yan (獻) and a you (卢), document the return of other emissaries (Beijing 1995:251-252).

As part of the most extensive analysis of the Liulihe cemetery to date, Sun (2001) examined the artistic styles of bronze and jade artifacts, traditionally seen as linked to social and political power. By also investigating both the spatial distribution of the graves and the placement and arrangement of artifacts in them, Sun concluded that the overall pattern of style and positioning closely resembled those seen in cemeteries in the central Zhou plain, which was the power base of the Zhou court (Sun 2001: 7879).

Sun further concludes that the findings from the Liulihe cemetery suggest a four-tiered social hierarchy. The highest-ranking individual was the Marquis of Yan. Though it is hard to obtain information since his tomb (IIM1193) was looted in antiquity, the bronze inscriptions and size of the tomb both suggest this individual was wealthier than the others (Sun 2001 : 119). The surviving artifacts connect the marquis to military power. Several ceremonial lacquer shields inlaid with bronze ornamental pao (泡) and bronze $j i$ (戟) and ge (戈) weapons surround the marquis' coffin. Two chariot pits (IIM202 and IIM1046) close by contained over 56 horse remains and 19 chariots (Sun 2001:120-121).

Based mainly on bronze vessel types and decorative style, Sun ascribes the second tier to upper-level aristocrats of the Yan state. These tombs contain more ceremonial bronze vessels for food and drink (e.g., six ding vessels in tomb IIM251) than are found in other tombs; the style of these vessels is similar to those found at the Zhou court (Sun 2001 : 121). Inscriptions commemorating envoys to the Zhou court were found on some of the bronzes. They describe some of the civic positions the tomb occupants might have held. Grave IIM1029 mostly contains weapons resembling those found in grave IIM1193, suggesting this individual also held a military position (Sun 2001 : 122).

The third level of Yan society was comprised of lower elites; their graves contained smaller numbers of food vessels ( $g u i$ 笽 or ding 鼎) and wine vessels ( $j u e$ 爵, $z h i$ 觶, or $z u n)$. This constellation of bronze vessels might reflect a departure from the standard Shang practice of combining $g u$ (解) and jue vessel types; it also implies the start of a new Western Zhou tradition (Sun 2001:123). Some graves also contained weapons and chariot ornaments, so a military role can be assigned to these lower elites (Sun $2001: 122$ ).

Individuals belonging to the lowest level of society were buried in smaller tombs that contained no bronze vessels. From the few bronze weapons found in some of these graves, Sun concludes that the owners were probably common soldiers. Interestingly, human sacrifices are found in some of these graves (Sun $2001: 123$ ). Such sacrifices are usually attributed to higher status members of society in Shang times. 


\section{THE LIMITATIONS OF STYLISTIC ANALYSIS}

It is clear that indigenous peoples existed in the area prior to the Zhou arrival. Indeed, the focus of the research outlined above has been ascribing ethnic identities to these peoples. Shennan, however, urges archaeologists to stop viewing cultures as "simply the contingent interrelations of different distributions produced by different factors" (Shennan 1989:13). This warning does not relate to the findings of similarities between the Zhou and Shang cultures and the cultures to which they are compared, but rather to the way these similarities are determined. Sun's (2001) focus on locating and interpreting mortuary remains within the established paradigm of Western Zhou expansion and cultural enculturation is not unique to research on Liulihe nor dissimilar from work done on other cemeteries that construct a four-tier hierarchy in Western Zhou society ( $\mathrm{Lu}$ and Yan $2005: 195)$. In this paradigm, social wealth and prestige are quantified according to the Zhou bureaucratic system; little is written about nonZhou elements and the ethnic identity of the local pre-Zhou indigenous residents is not given as much attention. The four-tier social construct is seen to exist only in the Zhou aristocratic world and to have been displayed through standard emblems. Although Sun (2001) has contributed to understanding stylistic divergences from the hegemonic traditions of the Western Zhou court, this kind of research limits us to the examination of similarities.

By analysing variation, archaeology can contribute greatly to understanding changes in identity. The point of inception should be breaking with predefined, allegedly natural, differentiating identity categories (Meskell 2001:188). As Chang argues, we must first "identify and characterize the social groups of archaeological cultures [and] ... look at archaeological sites as local social groups instead of as cultures or phases" (Chang 1958:324). In the next section, I present a statistical analysis of the Liulihe cemetery to provide a more comprehensive and nuanced reconstruction of the society that is less dependent on preordained categories of identity and cultural reference. ${ }^{5}$

\section{STATISTICAL ANALYSIS}

When conducting statistical analysis, one hopes to amass a comprehensive data set, preferably using the largest possible sample. However, for the sake of uniformity, only undisturbed and fully published graves are included in this analysis. The majority of the data come from the 1973-1977 excavations conducted by the Beijing cultural antiquity authorities (Beijing 1995). They uncovered a total of 61 graves: 32 in area I, and 29 in area II. Only the 48 undisturbed graves are included in this statistical analysis. ${ }^{6}$ Over 120 tombs were excavated during the 1981-1983 season, but to date no complete report has been published, so most of these could not be included. From a brief account of work published by Zhongguo et al. (1984), I was able to extract information on five more graves, all from the early Western Zhou period. Two more seasons, one in 1995 and the other in 1997, yielded data from more graves, six of which have been published (Beijing and Beijing 1996b; Beijing et al. 2000). The final data sample includes 59 graves, almost all of which are from the early Western Zhou period $(n=42)$; the remainder are from the middle $(n=8)$ and late $(n=9)$ periods.

I conducted a statistical examination using the excavators' bronze and pottery typological identifications. These findings are presented in Table 1. These descriptive 
statistics show that several graves are exceptionally rich. Grave IIM205 contains the highest number of artifacts, including the most bronze objects, of all the graves in the sample. Grave IIM205 also contains a high number of human and dog sacrifices, but it is not the largest tomb (that would be IIM253) nor does it contain the most pottery vessels (IM54) or jade artifacts (IM1029). This diversity in displays of wealth or prestige is evident in even the simple statistical distribution. It suggests that wealth or prestige could be displayed in various ways and that more than one burial custom was followed in the Liulihe cemetery.

Table i. Chart Summarizing Liulihe Cemetery Categories for all Periods $(\mathrm{n}=59)$.

\begin{tabular}{|c|c|c|c|c|c|c|}
\hline & MEAN & STD DEV & $\begin{array}{l}\text { STD ERR } \\
\text { MEAN }\end{array}$ & $\begin{array}{l}\text { UPPER } 95 \% \\
\text { MEAN }\end{array}$ & $\begin{array}{c}\text { LOWER 95\% } \\
\text { MEAN }\end{array}$ & HIGH GRAVE \\
\hline Grave size & $13.26 \mathrm{~m}^{3}$ & $17.44 \mathrm{~m}^{3}$ & $2.27 \mathrm{~m}^{3}$ & $17.80 \mathrm{~m}^{3}$ & $8.71 \mathrm{~m}^{3}$ & IIM253 $\left(124.3 \mathrm{~m}^{3}\right)$ \\
\hline Inner coffin & 0.93 & 0.25 & 0.031 & 0.99 & 0.86 & - \\
\hline Outer coffins & 0.69 & .62 & 0.08 & 0.85 & 0.53 & - \\
\hline Human sacrifices & 0.22 & 0.61 & 0.08 & 0.38 & 0.05 & 97Lh15M2 (3) \\
\hline Dog sacrifices & 0.07 & 0.84 & 0.11 & 0.94 & 0.50 & - \\
\hline Pottery & 4.62 & 5.57 & 0.72 & 6.07 & 3.17 & IM54 (36) \\
\hline Bronze artifacts & 6.40 & 14.38 & 1.87 & 10.15 & 2.65 & IIM205 (78) \\
\hline Jade artifacts & 1 & 2.18 & 0.28 & 1.56 & 0.43 & M1029 (11) \\
\hline Proto-Porcelain & 0.11 & 0.49 & 0.06 & 0.24 & 0.01 & IM52 (3) \\
\hline Total artifacts & 12.15 & 17.18 & 2.23 & 16.62 & 7.67 & IIM205 (88) \\
\hline
\end{tabular}

In order to gain a higher resolution of analysis, I inspected all the bronze artifacts, which are the most abundant single material artifact found in the cemetery. I divided them into the following subgroups: weapons, vessels, ornaments, drinking vessels, and items associated with chariot use and horse riding (Table 2).

Table 2. Bronze Artifacts of the Liulihe Cemetery.

\begin{tabular}{lllcccl}
\hline & MEAN & $\begin{array}{c}\text { STD } \\
\text { DEV }\end{array}$ & $\begin{array}{c}\text { SUM TOTAL OF } \\
\text { ARTIFACTS }\end{array}$ & $\begin{array}{c}\text { UPPER 95\% } \\
\text { MEAN }\end{array}$ & $\begin{array}{c}\text { LOWER 95\% } \\
\text { MEAN }\end{array}$ & HIGH GRAVE \\
\hline Vessels & 1.13 & 3.9 & 67 & 2.17 & 0.1 & IIM53 (24) \\
Drinking & 0.45 & 1.55 & 27 & 0.8 & 0.05 & IIM253 (9) \\
Weapons & 1.67 & 4.16 & 99 & 2.76 & 0.58 & M1029 (24) \\
Ornaments & 1.2 & 4.66 & 71 & 2.4 & 0.01 & IIM205 (31) \\
Riding & 2.08 & 6.3 & 123 & 3.73 & 0.43 & IIM205 (37) \\
\hline
\end{tabular}

No single grave held all the bronze artifact types or contained high quantities of bronze artifacts in two or more categories. This implies that wealth was not simply displayed by an abundance of all artifact types. A different pattern emerges by comparing areas I and II (Table 3).

Differences in the mean values of each category can be immediately observed. Area I has a higher mean value for pottery vessels and dog and human sacrifices. There is also a higher probability of finding waist pits in area I. These characteristics have 
Table 3. Comparison of Areas I and II Mean Values and Probability of Finding Waist Pits in a Specific Grave.

\begin{tabular}{lcc}
\hline & AREA I $(\mathrm{N}=32)$ & AREA II $(\mathrm{N}=27)$ \\
\hline${\text { Grave size } \mathrm{m}^{3}}^{3}$ & 10.25 & 16.82 \\
Inner coffin & 1 & 0.85 \\
Outer coffins & 0.75 & 0.62 \\
Human sacrifices & 0.40 & 0 \\
Dog sacrifices & 1.25 & 0.11 \\
Pottery & 6.65 & 2.22 \\
Bronze & 3.71 & 9.59 \\
Jade & 0.59 & 1.48 \\
Proto-Porcelain & 0.15 & 0.07 \\
Bone arrows & 0.68 & 0.55 \\
Vessels & 0.56 & 1.81 \\
Drinking & 0.34 & 0.59 \\
Weapons & 1.34 & 2.07 \\
Ornaments & 0.34 & 2.22 \\
Riding & 1.09 & 3.2 \\
Total artifacts & 11.12 & 13.37 \\
Probability of finding: & - & - \\
Waist pits & 0.65 & 0.11 \\
\hline
\end{tabular}

elsewhere been identified as typical of Shang burials. ${ }^{7}$ Area II displays higher mean values for grave size, total bronze artifacts, and all categories of bronze artifacts other than drinking vessels. Similar mean values are observed for the rest of the categories, especially the average number of grave goods found per grave. Basic statistical analysis thus initially points to different burial customs between the two areas. Apart from human sacrifices, however, all grave good categories were found in both areas. This means that although we might accept the separation of burial customs by area, the categories comprising this separation are not mutually exclusive, that is, they do not prohibit the existence of specific burial customs in any one area. This point is further highlighted by presenting the data in a bullet graph (Fig. 4).

Bullet graphs help reveal whether the differences in observed mean values between two samples are real or simply due to sampling error. ${ }^{8}$ In this test, a confidence level is assigned to the mean value of each of the four categories that display the greatest difference, allowing a comparison between the values of the two areas. There is a 95\% confidence level that the means observed between the two areas for both the dog and pottery categories are from samples with truly different mean values. In other words, there is less than a $5 \%$ chance that the difference in mean value between the two areas is due to random variance. In contrast, for both the size of graves and number of bronze artifacts (as well as for all the other categories) there is a confidence level of less than $75 \%$ that the difference in the mean value between the two areas is not simply due to random variation between the two data sets. This test shows that although basic statistical analysis provides a good starting point for understanding samples, it may be misleading (Baxter 1994; Drennan 1996, Shelach 2001; Shennan 1997).

Methods that search for broad patterns of similarity among the various categories were next employed to test correlations among the variables. Correlations may indicate that two variables (types of grave goods) are associated with the same social cat- 


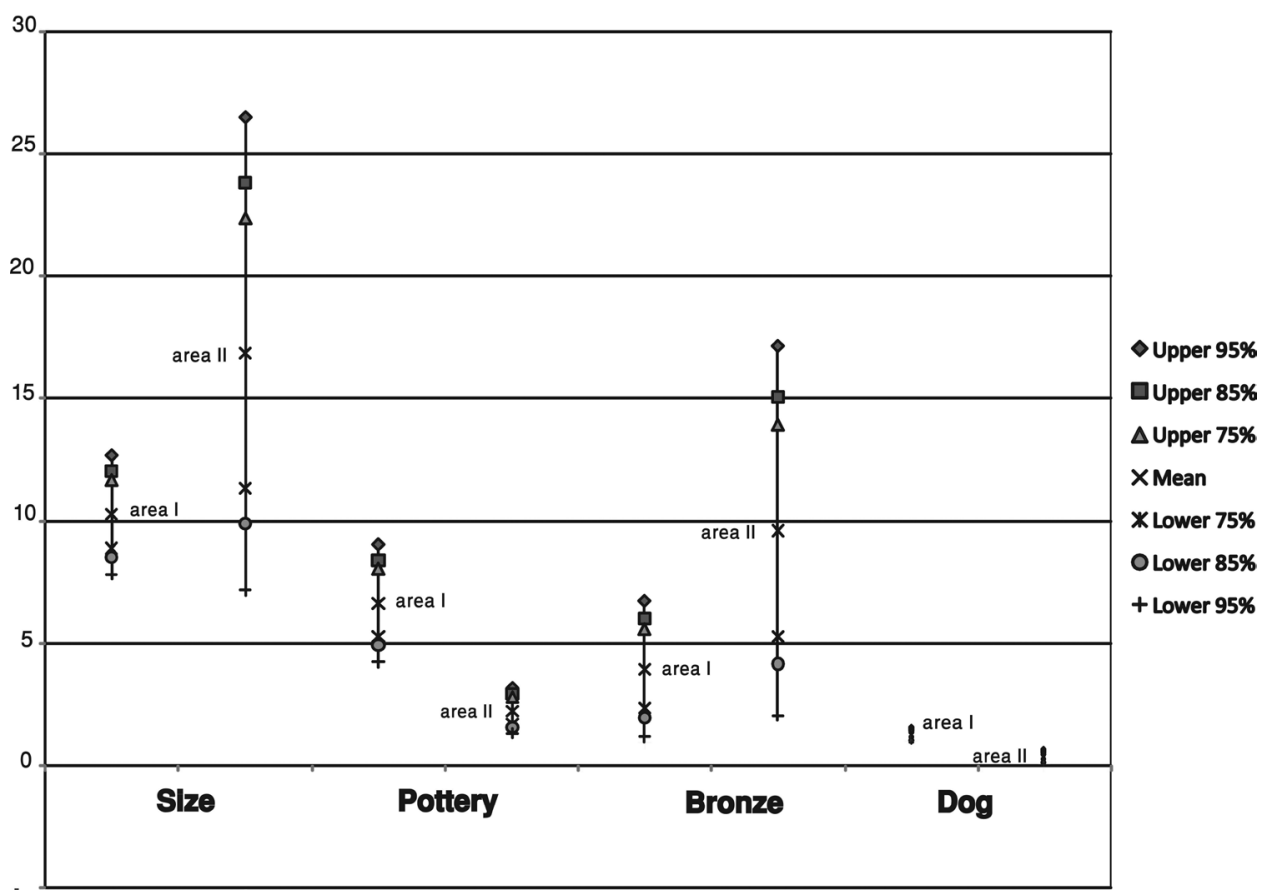

Fig. 4. Bullet graph comparing mean values of areas I and II.

egory or are often combined to mark the same identity. Table 4 displays a Pearson correlation matrix accounting for the covariance of paired categories utilized in the data sample.

Strong observable correlations are found between human sacrifices and the number of pottery vessels in any single grave. Because this correlation is not extended to other factors, it may represent an identity marker or burial habits of a social subgroup. Another strong correlation is that found between bronze artifacts and the size of the grave $\left(\right.$ in $\mathrm{m}^{3}$ ) and with the total number of artifacts in it. Grave size is also correlated with many other categories such as the number of jade artifacts, number of outer coffins, and total number of artifacts. This correlation might indicate the presence of a system with set rules wherein labor-intensive construction of graves and presence of artifacts is connected with the accumulation of wealth (Shelach 2001:70-72). Correlations not as intuitively obvious also can be seen between human sacrifices, protoporcelain vessels, and outer coffins, and between outer coffins and pottery vessels. Specific burial customs may link particular vessel types and other artifacts to mortuary practices. While finding correlations between variables can be illuminating, multivariate analysis enables us to discern prevalent patterns among a multitude of variables.

\section{MULTIVARIATE ANALYSIS}

Multivariate approaches such as factor analysis, principal component analysis (PCA), and cluster analysis seek to compress the information present in a large number of variables, allowing identification of correlations among all the variables in a data 


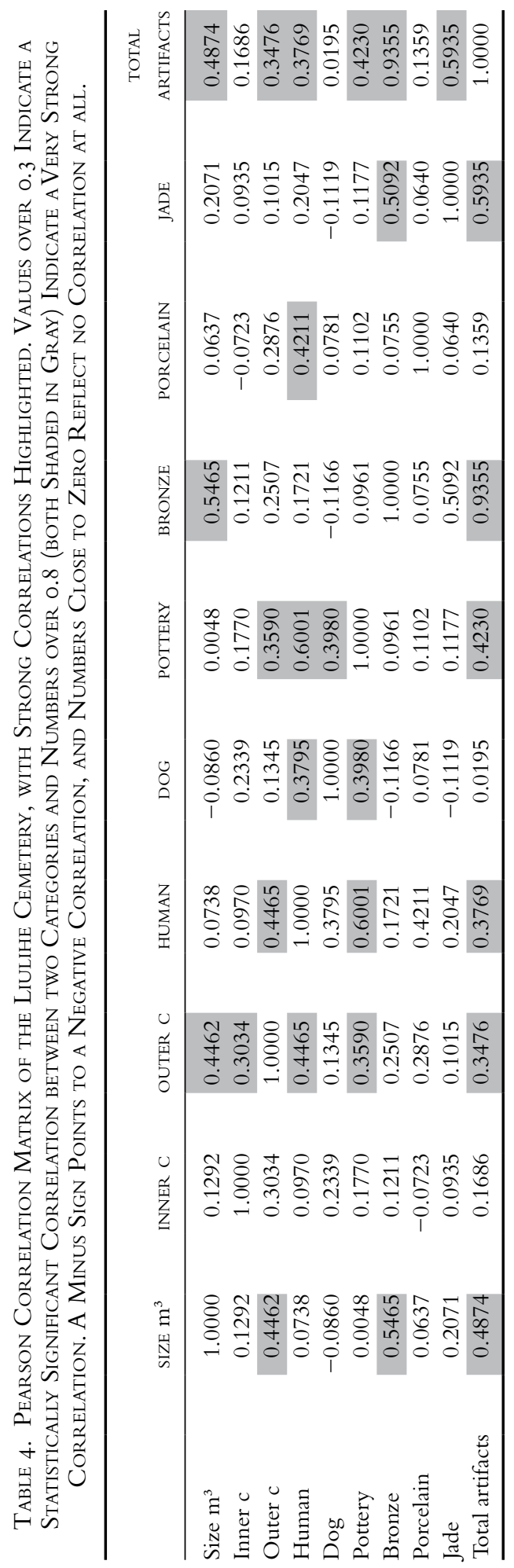


sample (Shennan 1997:242). ${ }^{9}$ Shelach $(2001,2008,2009)$ has demonstrated the relevance of employing factor analysis on assemblages from Bronze Age China. In factor analysis, a small number of factors are extracted via the correlations present among the observed variables, identifying dimensions that explain portions of the observed variability in the data set. The rationale is that if such underlying variation factors exist among the variables, factor analysis will not only extract the factors, but account for their salience and the amount of variance they explain (Shennan 1997 : 245). In simple terms, factor analysis allows a researcher to identify which variables are strongly related, that is, are likely the result of representing through different measures the same underlying dimension of variability. This underlying dimension of variability can then be examined in terms of its potential meaning in cultural and social terms. The relative importance of various dimensions of variability (in this case, variability in burial practices) can also be compared in terms of how they shape patterns in the data.

As factor analysis looks for distances on a geometrical matrix comprised of $\mathrm{p}$ axes ( $p$ being the number of variables being tested) between each observation, only continuous data categories were included in the analysis. Not all factors explain the same amount of the variance, and are not helpful in uncovering underlying factors latent in the burial sample. One of the most commonly used criteria for solving the numberof-components problem is the eigenvalue-one criterion, also known as the KaiserGuttman criterion. With this approach, only components with an eigenvalue greater than 1.00 are retained and interpreted (Kim and Mueller 1978). In this sample, only the first four factors retain an eigenvalue greater than 1.0, accounting for over $72 \%$ of the observed variance in the data set (Fig. 5). The observed correlation between the various categories can be seen in Table 5 .

By evaluating the correlations between the different categories comprising the factors, we can heuristically propose burial styles (linked to identities) manifested through the material remains found in any given tomb. In factor 1, the total number of artifacts - the number of jade artifacts and bronze artifacts of the ornamental and riding categories - were all positively and very strongly correlated, suggestive of the manner in which personal wealth and prestige were displayed. In factor 2, the grave size is positively correlated with the number of outer coffins, and both the number of bronze vessels, and bronze vessels associated with drinking. Factor 2 includes the

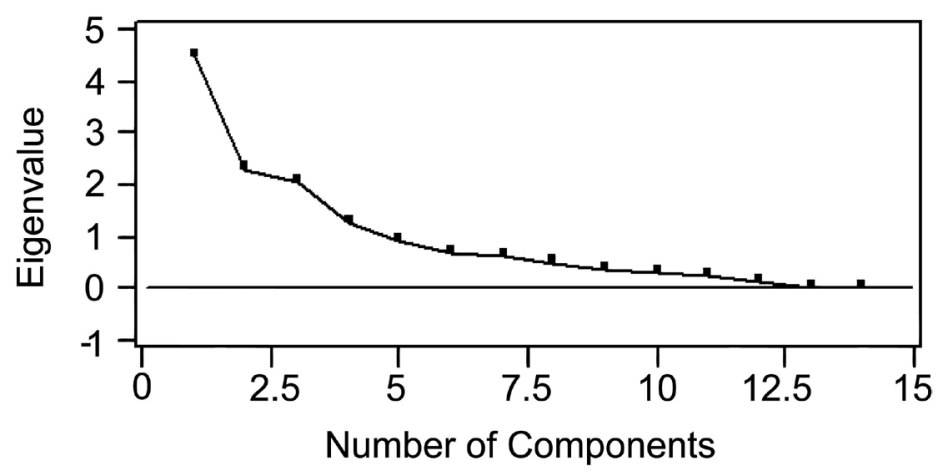

Fig. 5. Portions of variability explained by the different factors among the Liulihe cemetery burial data. 
Table 5. Factor Analyses of the Liulihe Graves. Numbers in Parentheses are the Variance Percentage Explained for Each Factor. Highlighted Factor Scores Within the Table Indicate Variables with High “Factor Loadings," i.e., Burial Attributes that Tend to Correlate and Taken Together Define a Distinct Dimension of Variability in Burial Practices.

\begin{tabular}{|c|c|c|c|c|}
\hline & $\begin{array}{l}\text { FACTOR I } \\
(32.04 \%)\end{array}$ & $\begin{array}{c}\text { FACTOR } 2 \\
(\mathrm{I} 6.62 \%)\end{array}$ & $\begin{array}{r}\text { FACTOR } 3 \\
(\mathrm{I} 4.82 \%)\end{array}$ & $\begin{array}{c}\text { FACTOR } 4 \\
(9.15 \%)\end{array}$ \\
\hline Grave size & 0.243603 & 0.705333 & -0.056068 & 0.144063 \\
\hline Inner coffin & 0.094760 & 0.086854 & 0.300605 & 0.022202 \\
\hline Outer coffin & -0.021147 & 0.493686 & 0.433012 & 0.357453 \\
\hline Human sacrifices & 0.084559 & 0.016872 & 0.664619 & 0.359343 \\
\hline Dog sacrifices & -0.118035 & -0.099165 & 0.521888 & -0.012908 \\
\hline Pottery & 0.088642 & 0.001553 & 0.929385 & 0.053619 \\
\hline Proto-Porcelain & -0.115908 & 0.108297 & 0.169407 & 0.559425 \\
\hline Jade & 0.700535 & -0.145382 & 0.007710 & 0.427506 \\
\hline Total artifacts & 0.826525 & 0.366366 & 0.334836 & 0.238433 \\
\hline Weapons & 0.368621 & 0.167148 & 0.026141 & 0.813456 \\
\hline Vessels & 0.175440 & 0.966842 & 0.013882 & -0.025192 \\
\hline Drinking & 0.029677 & 0.967985 & 0.037527 & 0.125639 \\
\hline Riding & 0.901141 & 0.232247 & -0.005963 & 0.033300 \\
\hline Ornaments & 0.857664 & 0.125384 & 0.005654 & -0.209163 \\
\hline
\end{tabular}

most labor-intensive categories of burial and grave investment components. It can be associated with ritualistic, public displays of wealth linked to social status and rank according to the Zhou bureaucratic order. Factor 3 correlates pottery (the dominant component of this factor) with human and dog sacrifices, as well as the number of outer coffins. This initially points to local customs or Shang-style customs as found by the excavators in area I. In Factor 4, the main category is weapons, which is somewhat correlated to proto-porcelain and jade artifacts; this may denote a military identity of the grave occupants. Figure 6 compares the means of each factor in areas I and II.

While the difference in mean value between factors 2 and 4 does not constitute significant separators between the two burial areas, the mean value of factor 3 is patently dissimilar. If factor 3 is accepted as representing the Shang tradition, it can be said that the occupants of area I adhered to this tradition to a considerable extent, while those buried in area II did not. However, the occupants in both areas displayed burial customs associated with the military. More importantly, occupants of both areas participated (in terms of burial practice rituals) in the Western Zhou political world. It is revealing that there is a confidence level of only $85 \%$ that the two burial areas differed with respect to factor 1 , that of personal wealth and prestige. Displays of wealth and prestige were somewhat more important in area II, but exist in area I.

There is greater oscillation in area II between the values of factors 1 and 2 among individual graves, while area I values are more unified. The opposite is true for factor 3 and, interestingly, for factor 4 (military association), as both samples are distributed similarly. That is, graves present differing scores in terms of the degree to which they manifest a certain dimension of variability (i.e., a specific factor). Table 6 below illus- 


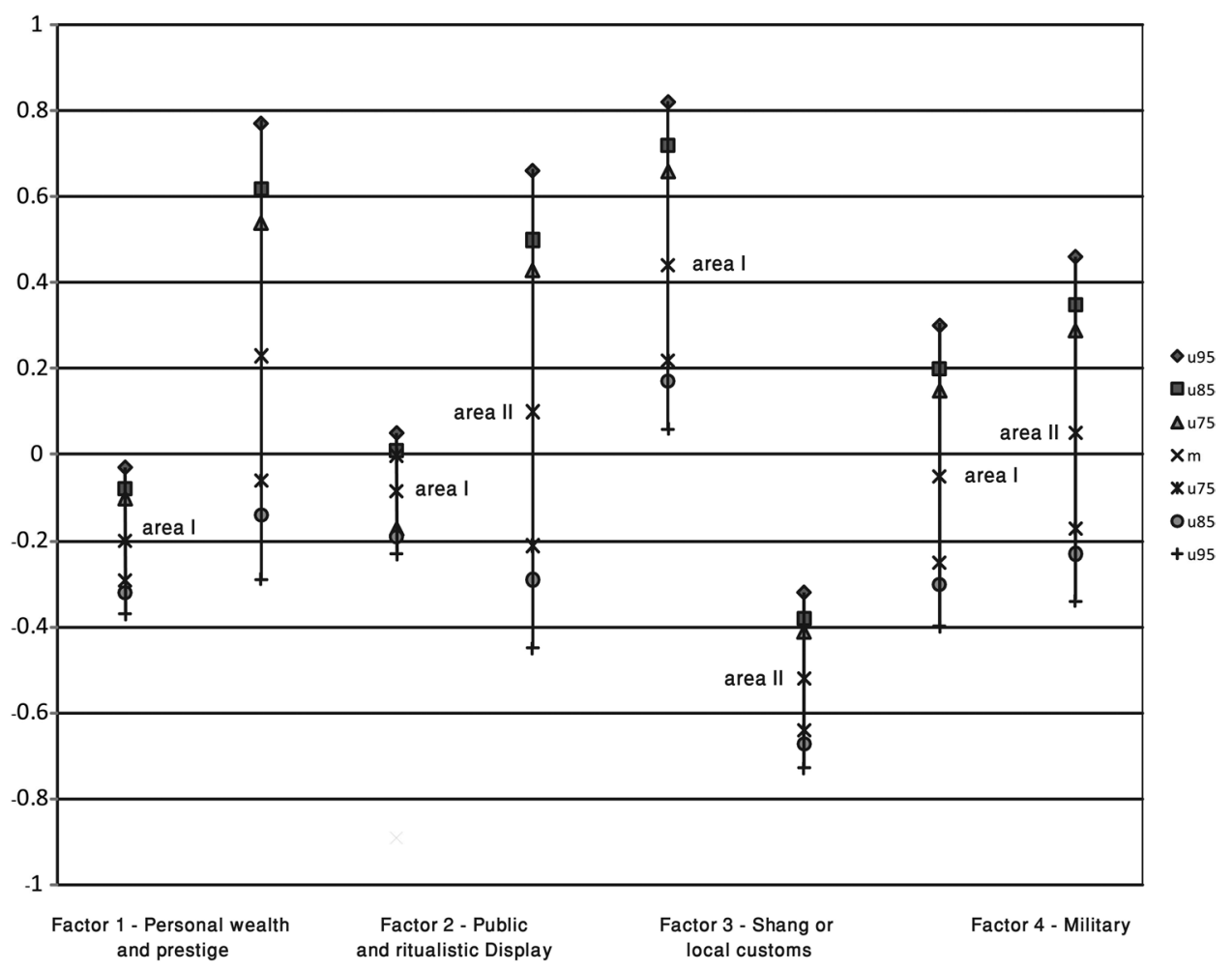

Fig. 6. Bullet graph comparing means of areas I and II for each of the four factors.

Table 6. Some High Scoring Graves of the Liulihe Cemetery (Note that Most Graves SCORED BETWEEN - I AND I ON EACH OF THE FOUR FACTORS).

\begin{tabular}{lcccr}
\hline & FACTOR I: & FACTOR 2: & FACTOR 3: & \\
& PERSONAL & PUBLIC AND & SHANG OR & \\
GEALTH AND & RITUALISTIC & LOCAL & FACTOR 4: \\
(GRAVEYARD AREA) & PRESTIGE & DISPLAY & CUSTOMS & MiLITARY \\
\hline IIM205 (2) & 6.23 & -0.74 & -0.56 & -0.13 \\
M1029 (2) & 2.47 & -0.69 & -2.14 & 4.51 \\
IIM251 (2) & -0.28 & 3.95 & -0.33 & 0.75 \\
IIM253 (2) & 0.68 & 3.88 & -0.2 & -1.18 \\
IM54 (1) & 1.43 & -0.52 & 4.97 & -0.77 \\
IM52 (1) & -0.86 & 1.4 & 1.33 & 3.69 \\
\hline
\end{tabular}

trates this by presenting the four factor scores for different individual graves in the Liulihe cemetery.

Table 6 demonstrates that several graves have high scores on some factors but not on others. Some graves score high on only one factor and low on the others. If indeed these factors reflect identity packages displaying various levels of social status and rank, 
it is not surprising that different elements of society chose to emphasize certain aspects of identity, while others upheld and displayed different ones. It is interesting to note that graves from both areas score high on each of the parameters, a result that further undermines a rigid dichotomization of Yan society based on ethnic (i.e., 'Shang' or 'Zhou') characteristics.

\section{IDENTITY AND ITS FORMATION IN THE YAN STATE}

The Western Zhou period provides a unique test case for studying the process of identity formation. Zhou frontier polities included a mix of Zhou lineages vying to acculturate local (non-Zhou) indigenous populations. Rawson (1999:384-385) finds that the initial great strength of the Zhou lay in their ability to muster and express power materially by incorporating both local and previous Shang elements as they enlisted the support of local populations.

In her reconstruction of the Yan court, Sun (2003) argues that Yan elite employed a mixture of strategies for establishing political and cultural domination. Foremost, they drew power from their connections to the Zhou court. Many of the Yan bronzes are identical in style to those found in the Central Plain; some are thought to have been cast there and transported to the Yan state (Sun 2003:763). Various bronze vessels include inscriptions documenting envoys and gifts sent to the Zhou court (Sun 2003:763-766). This is how power was displayed in the Central Plain. That and the fact that some vessels were actually cast at the Zhou court further attest to an emphasis among the Yan elite of connection to the main seat of Zhou government power (Sun 2003, Sun 2006:164-165). Sun also argues that following the establishment of the Yan polity, local customs changed. Local populations adopted aspects of the introduced Zhou material culture as a way of tying themselves to the Yan state, and they acquired prestige by displaying Yan symbols (Sun 2006:170-172). For example, northern-style artifacts (i.e., daggers and jewelry) were found alongside Zhou-style bronze vessels in an elite local woman's grave (Sun 2003 : 768). Similarly the finding of a Kazuo (喀左) bronze hoard in the Zhou style deep in Upper Xiajiadian territory may reflect either an attempt to set up Yan court posts in the north or an adoption of Zhou elements by locals (Sun 2003:769).

Sun's (2001, 2003, 2006) analysis is based on stylistic similarities between Yan bronze and jade artifacts and those prevalent at the Zhou court. Although most of Sun's analysis centers on higher Yan elite graves that contain such artifacts (such as the grave of the Marquis of Yan), it provides invaluable insight into the political culture of the Yan court. ${ }^{10}$ This kind of approach excels at comparing data samples around predefined categories and measuring exactly how similar or different they are. Indeed, this method located the graves in the Liulihe cemetery that most closely followed Zhou ritual customs. However, projecting backwards to attribute this elite style to the entire population and then claiming it exemplifies "Yan culture" is a somewhat circular argument. This bias can be avoided by looking for general trends in the entire cemetery population and then observing individual cases. This method results in a more balanced view of the widespread burial customs throughout the cemetery. It also facilitates a reevaluation of the relevance of predefined categories of identity.

The statistical approach employed here demonstrates the advantages of first examining the mortuary locus as a whole. Only after describing the diverse manners in 
which wealth, prestige, and status were displayed can we proceed to evaluate the identities these displays promulgate. The findings discussed in this article fit Eisenstadt and Giesen's (1995) collective identity model. They argue that many forms of group identity are in a constant state of flux and that group-specific power relations and resource procurement and distribution all contribute to the construction of the symbolic codes that distinguish social groups (Eisenstadt and Giesen 1995 :76-77). The key here is to acknowledge that the identity signifiers (i.e., burial packets) evident in the four different factors are not customs along which Yan society was clearly segmented.

A different picture of Yan society emerges from the bottom-up approach followed in this article. It is not defined solely by the amount of Zhou or non-Zhou styles exhibited. While elements that can be attributed to Zhou culture were present in the cemetery, they were not mutually exclusive with non-Zhou elements nor were they formally practiced exclusively by those buried in one area of the cemetery. No single style of burial was used by the Western Zhou-period occupants of Liulihe cemetery. On the contrary, the burial style found at Liulihe is comprised of combinations of various forms of identity markers. This casts doubt on any theory of complete and immediate incorporation of the indigenous population following arrival of the Zhou people. In his survey of Zhou cultural development, von Falkenhuasen (2006:239) finds that identity was not an immutable essence for each individual in the Zhou world but a malleable feature of social existence. Rather than a "melting pot" process that created a single shared identity, von Falkenhausen argues that by the Eastern Zhou period differences between groups had not diminished but actually had become more acute, with non-Zhou elements of material culture flaunted as symbols of unique identities $(2006: 241)$. Indeed, at Liulihe during the middle and late periods, burial customs differ more significantly from the prevailing customs of the central plain and Zhou court than those in the early period. In the middle and late periods the Lieding system (列鼎), involving interment of standardized bronze vessel sets reflecting rank among western Zhou aristocracy, was not followed; and local pottery dominated the burial assemblages (Chai 1995).

These examples illustrate the complexity of assigning identity and clearly defined characteristics solely on the basis of material culture. Far from displaying direct and simple links between "pots and people," collective identity at Liulihe emerges as a constant renegotiation of boundaries between different groups (Barth 1969). Demarcation of group territories and identities is not only accentuated at junctions of contact, but is created by such contact. We can thus analyze the factors put into play by those seeking to establish themselves in a newly formed polity, including new and old customs, attributes, and ideas. When similar analytic tools are used to examine the mortuary assemblages of the central plain and other cemeteries of the Zhou period, I believe they will be no less rewarding.

\section{ACKNOWLEDGMENTS}

I would like to thank Gideon Shelach for his comments, support, and mostly for his patience rereading earlier versions of this article. Rowan Flad provided additional support and wonderful insight on how to make this paper stronger. I would also like to thank Beverly Lewin for her many remarks and suggestions. Finally I would like to thank the reviewers for their suggestions on how to make this article clearer and more accessible. 


\section{NOTES}

1. See Lu and Yan (2005) for an excellent overview.

2. Von Falkenhausen (2006) provides a critical overview on the ascription of ethnicity on the basis of mortuary data.

3. For a complete overview, see Wu (2004:204-206).

4. Unfortunately, very few skeletal remains have survived. From the few that have been excavated, it appears that laying the deceased facing upwards was the norm (Beijing 1995:6).

5. Eisenstadt and Giesen's (1995) work on how collective identities are constructed also inspired this research.

6. Unfortunately, tomb IIM1193 attributed to the Duke of Yan could not be included as it had been robbed in the past.

7. See Tang 1999 for an overview of Shang style (Yinxu period 1200-1046 B.C.E.) burials and von Falkenhausen 2006:194 on the problematic nature of ascribing burial styles as that of Shang.

8. For an overview of bullet graphs, see Drennan 1996:151-153.

9. The employment of factor analysis in archaeology was popular in the 1970s, but has since somewhat diminished (McClellan 1979; Tainter 1975). Cowgill (1977) critically examined the extensive use of quantitative methods in archaeology and brought about a remission in the employment of factor analysis and other multivariate methods. Others agreed that archaeology should not rely so heavily on quantitative analysis, but lamented that neglecting PCA and factor analysis might be an example of the "baby which has been lost with the bath water" (Baxter 1994:86).

10. For a similar analysis, see Zhongguo and Beijing (1990).

\section{REFERENCES CITED}

BARnes, Gina L.

1999 Rise of Civilization in East Asia. London: Thames \& Hudson.

BARTh, Frederick

1969 Introduction, in Ethnic Groups and Boundaries: The Social Organization of Culture Difference: 9-38, ed. F. Barth. Boston: Little Brown.

BAXTER, Michael J.

1994 Exploratory Multivariate Analysis in Archaeology. Edinburgh: Edinburgh University Press.

Beijing Daxue Kaoguxuexi and Beijing Wenwu Yanjiusuo 北京大学考古学系与北京文物研究所

1996a 1995 nian Liulihe Zhou dai juzhi fajue jianbao 1995 年琉璃河周代居址发掘简报 [1995 excavation season of the Zhou dynasty dwelling site at Liulihe]. Wenwu 文物 [Cultural Relics] $6: 4-15$.

1996 b 1995 nian Liulihe yizhi muzang qu fajue jianbao 1995 年琉璃河遗址墓葬区发掘简报 [1995 excavation season of the cemetery at the Liulihe site]. Wenwu 文物 [Cultural Relics] 6:16-27.

Beijing Shi Wenwu Yanjiusuo 北京市文物研究所

1995 Liulihe Xi Zhou Yanguo mudi, 1973-1977 琉璃河西周燕国墓地 1973-1977 [The Yan State Cemetery of the Western Zhou Period at Liulihe, 1973-1977]. Beijing 北京: Wenwu chubanshe 文物出版社.

1997 Beijing jiancheng 3040 nian ji Yan wenming guoji xueshu yantaohui huiyi zhuanji 北京建城 3040 年暨燕文明国际学术研讨会会议专辑 [Seminar in Celebration of 3040 Years since the Founding of the City of Beijing and Continued Research on Yan Civilization]. Beijing 北京: Beijing Yanshan Chubanshe 北京燕山出版社.

Beijing Shi Wenwu Yanjiusuo, Beijing Daxue Kaogu Wenbo Xueyuan, and Zhongguo ShehuiKEXUEYUAN 北京市文物研究所, 北京大学考古文博学院, 与中国社会科学院

20001997 nian Liulihe yizhi muzang fajue jianbao 1997 年琉璃河遗址墓葬发掘简报 [A brief report on the excavation of burials at Liulihe in 1997]. Wenwu 文物 [Cultural Relics] 11:3238.

Chai XiaOming 柴小明

1995 Huabei diqu Xi Zhou taoqi chulun 华北地区西周陶器初论 [A short discussion on western Zhou ceramics in the Northern zone], in Yan wenhua yanjiu lunwen ji 燕文化研究论文集: 105-116, ed. Chen Guang 陈光. Beijing 北京: Zhongguo shehui kexue 中国社会科学.

Chang, Kwang Chin

1958 Study of the Neolithic social groupings: Examples from the New World. American Anthropologist 60:298-334. 
Cowgill, George L.

1977 The trouble with significance tests and what we can do about it. American Antiquity $42: 350-368$.

DRENNAN, Robert D.

1996 Statistics for Archaeologists: A Commonsense Approach. New York: Plenum Press.

Eisenstadt, Shmuel N., and Bernhard Giesen

1995 The construction of collective identity. Archives Européennes de Sociologie 36:72-102.

GuO, DASHUN

1996 Lower Xiajiadian culture, in The Archaeology of Northeast China: 147-181, ed. S. M. Nelson. London and New York: Routledge.

HODDER, IAN

1978 Simple correlation between material culture and society: A review, in The Spatial Organization of Culture: 3-24, ed. I. Hodder. Pittsburgh, PA: University of Pittsburgh Press.

Hsu, Cho-yun, and Katheryn M. LindufF

1988 Western Chou Civilization. New Haven: Yale University Press.

INSOLL, TIMOTHY

2007 Introduction: Configuring identities in archaeology, in The Archaeology of Identities: A Reader: 1-18, ed. T. Insoll. New York: Routledge.

Kim, Jae-On, and Charles Mueller

1978 Introduction to Factor Analysis: What It Is and How to Do It. Quantitative Applications in the Social Sciences, Paper 13. Beverly Hills, CA: Sage Publications.

Li, BOQIAN

2000 Stages and regions of Bronze Culture in China, in The Beginning of Metallurgy in China: 153174, ed. K. M. Linduff. New York: Edwin Mellen Press.

2004 Patterns of development among China's Bronze Cultures, in New Perspectives on China's Past: Chinese Archaeology in the Twentieth Century: 188-199, ed. Yang Xiaoneng. London: Yale University Press.

LI, FENG

1997 Ancient reproductions and calligraphic variations: Studies of Western Zhou bronzes with 'identical' inscriptions. Early China 22:1-41.

2006 Landscape and Power in Early China: The Crisis and Fall of the Western Zhou 1045-771 BC. Cambridge: Cambridge University Press.

2008 Bureaucracy and the State in Early China: Governing the Western Zhou 1045-771 BC. Cambridge: Cambridge University Press.

Lu, Liancheng, And Wenming Yan

2005 Society during the Three Dynasties, in The Formation of Chinese Civilization: An Archaeological Perspective: 141-201, ed. Sarah Allan. New Haven: Yale University Press.

LuOYAng SHi Wenwu GongzuOdui 洛阳市文物工作队

2002 Luoyang Beiyao Xi Zhou mu 洛阳北窑西周墓 [The western Zhou cemetery at Beiyao, Luoyang]. Beijing 北京: Wenwu chubanshe 文物出版社.

McClellan, Thomas L.

1979 Chronology of the "Philistine" burials at Tell el-Far'ah (South). Journal of Field Archaeology $6: 57-73$.

Meskell, LynN

2001 Archaeologies of identity, in Archaeological Theory Today: 187-213, ed. I. Hodder. Cambridge: Polity Press.

Meskell, Lynn, and Robert W. Preucel

2004 Identities, in A Companion to Social Archaeology: 121-141, ed. Lynn Meskell and Robert W. Preucel. Oxford: Blackwell.

Pearson, Mike P.

1999 The Archaeology of Death and Burial. College Station: Texas A\&M Press.

RAWSON, JESSICA

1999 Western Zhou archaeology, in The Cambridge History of Ancient China: From the Origins of Civilization to 221 B.C.: 352-449, ed. Michael Loewe and Edward Shaughnessy. Cambridge: Cambridge University Press. 
Shandong Sheng Wenwu KaOgu Yanjiusuo 山东省文物考古研究所

1982 Qufu Lugu chengshi 曲阜鲁国故城 [The ancient city of Qufu of the Lu state]. Jinan 济南: Qilushushe 齐鲁书社.

\section{SHAUghnessy, EDWARD}

1999 Western Zhou history, in The Cambridge History of Ancient China: From the Origins of Civilization to 221 в.C.: 292-351, ed. Michael Loewe and Edward Shaughnessy. Cambridge: Cambridge University Press.

2004 Hoards and family histories in Qishan County, the Zhouyuan, during the Western Zhou Dynasty, in New Perspectives on China's Past: Chinese Archaeology in the Twentieth Century: 254-267, ed. Xiaoneng Yang. New Haven: Yale University Press.

Shelach, GideOn

2001 Apples and oranges? Cross-cultural comparison of burial data from northeast China. Journal of East Asian Archeology 3(3-4) : 53-90.

2008 Violence on the frontiers? Sources of power and socio-political change at the easternmost parts of the Eurasian steppes during the early first millennium BCE, in Social Complexity in Prehistoric Eurasia: 241-271, ed. Bryan Hanks and Kathryn Linduff. Cambridge: Cambridge University Press.

2009 Prehistoric Societies on the Northern Frontiers of China: Archaeological Perspectives on Identity Formation and Economic Change during the First Millennium BCE. London: Approaches to Anthropological Archaeology Series, Equinox Press.

Shennan, Stephen J.

1989 Introduction: Archaeological approaches to cultural identity, in Archaeological Approaches to Cultural Identity: 1-32, ed. S. Shennan. London and New York: Routledge.

1997 Quantifying Archaeology, 2nd ed. Edinburgh: Edinburgh University Press.

Sun, Yan

2001 Negotiating Cultural and Political Control in North China: Art and Mortuary Ritual and Practice of the Yan at Liulihe during the Early Western Zhou Period. PhD diss., University of Pittsburgh.

2003 Bronzes, mortuary practice and political strategies of the Yan during the early Western Zhou period. Antiquity $77: 761-770$.

2006 Cultural and political control in North China: Style and use of the bronzes of Yan at Liulihe during the Early Western Zhou, in Contact and Exchange in the Ancient World: 215-237, ed. Victor H. Mair. Honolulu: University of Hawai'i Press.

TAINTER, Joseph A.

1975 Social inference and mortuary practices: An experiment in numerical classification. World Archaeology $7: 1-15$.

TANG, JigEN

1999 The burial ritual of the Shang Dynasty: A reconstruction, in Exploring China's Past: 173-181, ed. Roderick Whitfield and Wang Tao. London: Saffron Press.

VON FALKenhausen, Lothar

1995 The regionalist paradigm in Chinese archaeology, in Nationalism, Politics, and the Practice of Archaeology: 198-217, ed. Philip Kohl and Clare Fawcett. Cambridge: Cambridge University Press.

2006 Chinese Society in the Age of Confucius (1000-250 BC): The Archeological Evidence. Los Angeles: Cotsen Institute of Archaeology, UCLA.

Wu, EN

2004 Issues concerning Northern Bronze Cultures in China, in New Perspectives on China's Past: Chinese Archaeology in the Twentieth Century: 200-215, ed. Yang Xiaoneng. London: Yale University Press.

Zhongguo Shehui Kexueyuan Kaogu Yanjiusuo, Beijing Shi Wenwu Gongzuodui, and Liulihe KAOGUDUI 中国社会科学院考古研究所, 北京市文物工作队, 琉璃河考古队

1984 1981-1983 nian Liulihe Xi Zhou Yan guo mudi fajue jianbo 1981-1983 年琉璃河西周燕国 墓地发掘简报 [A brief report on the 1981-1983 excavation seasons of the western Zhou Yan state cemetery at Liulihe] Kaogu 考古 [Archaeology] 5:404-416.

Zhongguo Shehui Kexueyuan Kaogu Yanjiusuo and Beijing Wenwu Yanjiusuo 中国社会科学院 考古研究所与北京文物研究所

1990 Beijing shi Liulihe 1193 damu fajue jinbao 北京市琉璃河 1193 大墓发掘简报 [A brief excavation report of burial 1193 at Liulihe, Beijing]. Kaogu 考古 [Archaeology] 5:20-31. 


\section{ABSTRACT}

Questions of identity are of paramount importance in research of the Western Zhou period, both in the central plain and among its vassal states. Yet most research done to date has focused on the Zhou bureaucratic order and government. These analyses have been very successful in delineating political culture, administration, and kinship ties, and have provided important information on elite taste and customs. However, they have paid less attention to uncovering other social groupings and relations, and do not systematically address the ways in which local identities were exercised or displayed. This article presents a multivariate statistical analysis of the Liulihe cemetery of the Western Zhou state of Yan. This analysis uncovers new elements comprising the complex social makeup and identity of the Liulihe occupants. These findings provide a richer understanding of the Yan society compared with the traditional approach that centered on the delineation of Zhou political elements and ethnic characteristics. A more intricate society emerges, one not solely defined by the amount of Zhou style it exhibited. KeYwORDs: Western Zhou, ethnicity, identity, multivariate analysis, mortuary practices. 